\title{
Groundwater Quality in the San Diego Drainages Hydrogeologic Province, California
}

More than $\mathbf{4 0}$ percent of California's drinking water is from groundwater. To protect this vital resource, the State of California created the Groundwater Ambient Monitoring and Assessment (GAMA) Program. The Priority Basin Project of the GAMA Program provides a comprehensive assessment of the State's groundwater quality and increases public access to groundwater-quality information. The San Diego Drainages Hydrogeologic Province (hereinafter referred to as San Diego) is one of the study units being evaluated.

\section{The San Diego Study Unit}

The San Diego study unit is approximately 3,900 square miles and consists of the Temecula Valley, Warner Valley, and 12 other alluvial basins (California Department of Water Resources, 2003). The study unit also consists of all areas outside defined groundwater basins that are within 3 kilometers of a public-supply well. The study unit was separated, based primarily on hydrogeologic settings, into four study areas: Temecula Valley, Warner Valley, A lluvial B asins, and Hard Rock (Wright and others, 2005). The sampling density for the Hard Rock study area, which consists of areas outside of groundwater basins, was much lower than for the other study areas. Consequently, aquifer proportions for the Hard Rock study area

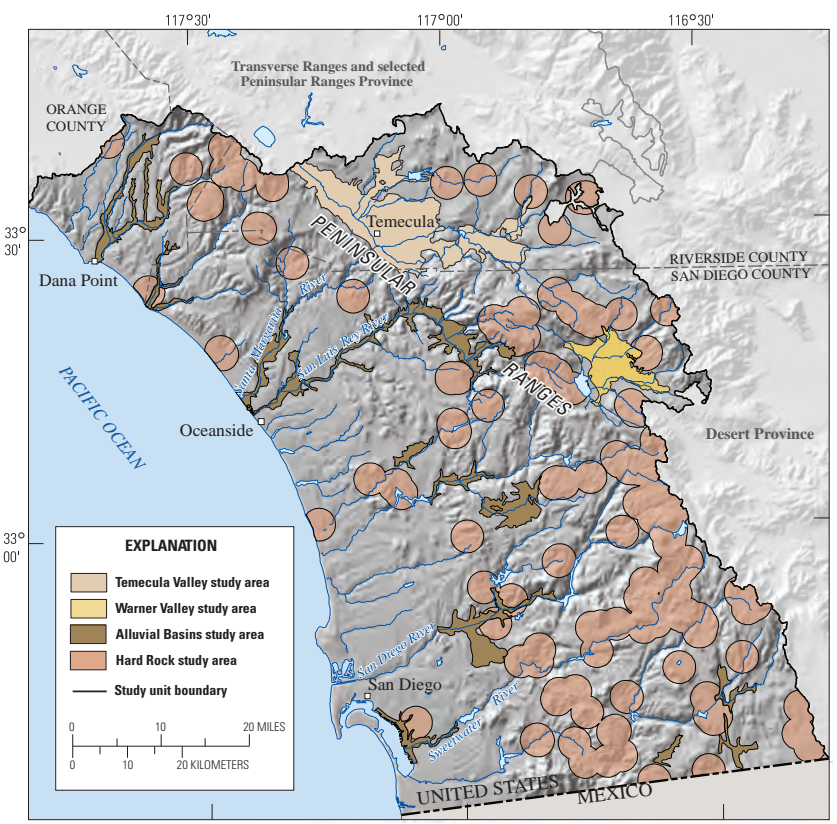
are not used to calculate the aquifer proportions shown by the pie charts. An assessment of groundwater quality for the Hard Rock study area can be found in Wright and B elitz, 2011.

The temperatures in the coastal part of the study unit are mild with dry summers, moist winters, and an average annual rainfall of about 10 inches. The temperatures in the mountainous eastern part of the study unit are cooler than in the coastal part, with an annual precipitation of about 45 inches that occurs mostly in the winter. The primary aquifers consist of Quaternary-age alluvium and weathered bedrock in the Temecula Valley, Warner Valley, and A lluvial Basins study areas, whereas in the Hard Rock study area the primary aquifers consist mainly of fractured and decomposed granite of M esozoic age. The primary aquifers are defined as those parts of the aquifers corresponding to the perforated intervals of wells listed in the California Department of Public Health (CDPH) database. Public-supply wells typically are drilled to depths between 200 and 700 feet, consist of solid casing from the land surface to a depth of about 60 to 170 feet, and are perforated, or consist of an open hole, below the solid casing. Water quality in the shallow and deep parts of the aquifer system may differ from water quality in the primary aquifers.

M unicipal water use accounts for approximately 70 percent of water used in the study unit; the majority of the remainder is used for agriculture, industry, and commerce. Groundwater accounts for approximately 8 percent of the municipal supply, and surface water, the majority of which is imported, accounts for the rest. Recharge to groundwater occurs through streamchannel infiltration from rivers and their tributaries, infiltration in engineered recharge basins, and infiltration of water from precipitation and irrigation. The primary source of discharge is water pumped from wells.

\section{Overview of Water Quality}
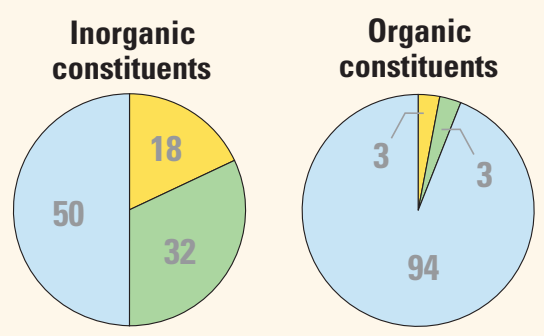

CONSTITUENT CONCENTRATIONS

High $\bigcirc$ Moderate $\bigcirc$ Low or not detected

Values are a percentage of the area of the primary aquifers with concentrations in the three specified categories. Values on pie chart may not equal 100 due to rounding of percentages.

GAM A's Priority B asin Project evaluates the quality of untreated groundwater. However, for context, benchmarks established for drinking-water quality are used for comparison. Benchmarks and definitions of high, moderate, and low concentrations are discussed in the inset box on page 3 .

$M$ any inorganic constituents occur naturally in groundwater. The concentrations of the inorganic constituents can be affected by natural processes as well as by human activities. In the alluvial-filled basins of the San Diego study unit, one or more inorganic constituents were present at high concentrations in 18 percent of the primary aquifers and at moderate concentrations in 32 percent of the primary aquifers.

Organic constituents are in products used in the home, business, industry, and agriculture. Organic constituents can enter the environment through normal usage, spills, or improper disposal. In the alluvium-filled basins of the study unit, one or more organic constituents were present at high concentrations in 3 percent of the primary aquifers and at moderate concentrations in 3 percent of the primary aquifers. 


\section{INORGANIC CONSTITUENTS}

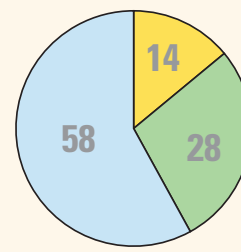

\section{Trace and minor elements}

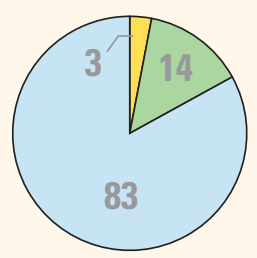

\section{Radioactive} constituents
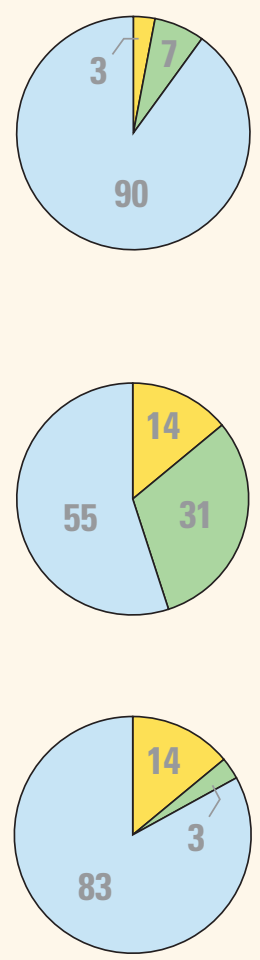

SPECIAL-INTEREST CONSTITUENTS

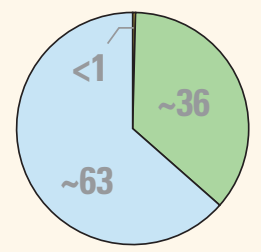

\section{Inorganic Constituents with Human-Health Benchmarks}

Trace and minor elements are naturally present in the minerals in rocks and soils, and in the water that comes into contact with those materials. In the all luvialfilled basins in the San Diego study unit (Temecula Valley, Warner Valley, and A lluvial B asins), one or more trace el ements were present at high concentrations in about 14 percent of the primary aquifers. Vanadium, arsenic, and boron were detected at high concentrations in at least 4 percent of the primary aquifers. A ntimony was detected at high concenetrations in about 3 percent of the primary aquifers.

R adioactivity is the release of energy or energetic particles during structural changes in the nucleus of an atom. M ost of the radioactivity in groundwater comes from decay of naturally occurring isotopes of uranium and thorium in minerals in the sediments of the aquifer. Radioactivity from the radioactive constituents occurred at high concentrations in 3 percent of the primary aquifers, and at moderate concentrations in 14 percent of the primary aquifers. Gross-alpha radioactivity was detected at high concentrations in 3 percent of the primary aquifers.

N utrients, such as nitrate and nitrite, are naturally present at low concentrations in groundwater. High and moderate concentrations generally occur as a result of human activities, such as applying fertilizer to crops. Septic systems and livestock, when in concentrated numbers, also produce nitrogenous waste that can leach into groundwater. N utrients, in the form of nitrate, were present at high concentrations in 3 percent of the primary aquifers, and at moderate concentrations in about 7 percent of the primary aquifers.

\section{Inorganic Constituents with Non-Health Benchmarks}

(Not included in water-quality overview charts shown on the front page)

Some constituents, such as total dissolved solids (TDS), affect the aesthetic properties of water, such as taste, color, and odor. Other constituents, such as iron and manganese, can create nuisance problems, such as scaling and staining.

The State of California has a recommended an upper limit for TDS in drinking water. In the alluvial-fill basins of the San Diego study unit, TDS was present at high concentrations (greater than the upper limit) in 14 percent of the primary aquifers, at moderate concentrations (between the recommended and upper limit) in 31 percent of the primary aquifers, and at low concentrations (less than the recommended limit) in 55 percent of the primary aquifers.

I ron and manganese are naturally occurring elements, and one or both were present at high concentrations in 14 percent of the primary aquifers. Iron or manganese (or both) were present at moderate concentrations in 3 percent of the primary aquifers, and at low concentrations in about 83 percent of the primary aquifers.

\section{Perchlorate, 1,4-dioxane, and N-Nitrosodimethylamine (NDMA)}

(Not included in water-quality overview charts shown on the front page)

Perchlorate, 1,4-dioxane, and NDM A are of special interest in California because these constituents recently have been detected in groundwater and are considered to have the potential to affect the quality of drinking-water supplies. Their presence in groundwater is monitored by the California Department of Public Health (http://www.cdph.ca.gov). In the San Diego study unit, perchlorate was detected at high concentrations in less than 1 percent of the primary aquifers and at moderate concentrations in about 36 percent of the primary aquifers. 1,4-dioxane and NDM A were not detected. 


\section{RESULTS: Groundwater Quality in the San Diego Study Unit}

\section{ORGANIC CONSTITUENTS}

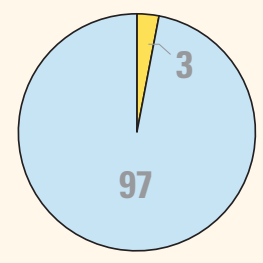

\section{Gasoline components}
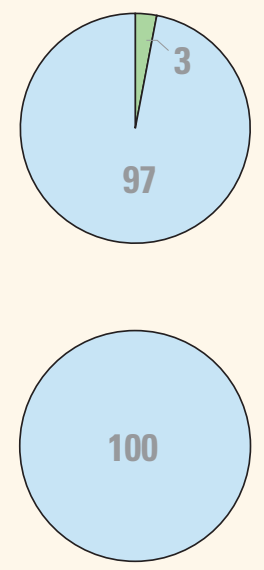

\section{Trihalomethanes and other VOCs}

\section{Organic Constituents}

The Priority Basin Project uses laboratory methods that can detect low concentrations of volatile organic compounds (VOCs) and pesticides, far below human-health benchmarks. The presence of V OCs and pesticides detected at these low concentrations can be used to trace water from the landscape into the aquifer system.

\section{Volatile Organic Compounds with Human-Health Benchmarks}

VOCs are in many household, commercial, industrial, and agricultural products and are characterized by their tendency to volatilize into the air.

Gasoline components are compounds that constitute gasoline, or are additives, such as methyl tert-butyl ether (M TBE). In the alluvium-filled basins of the San Diego study unit, gasoline components were present at high concentrations in 3 percent of the primary aquifers. The gasoline component detected at high concentration was M TBE. No gasoline components were detected at moderate concentrations.

Solvents are used for a number of purposes, including manufacturing and cleaning. Solvents were not detected at high concentrations, but were detected at moderate concentrations in 3 percent of the primary aquifers. The solvent detected at moderate concentrations was 1,2-dichloropropane.

Trihalomethanes may form during municipal water purification and enter groundwater by the infiltration of landscape irrigation water. Trihalomethanes were detected only at low concentrations in the primary aquifers.

Other V OCs, including organic synthesis reagents and refrigerants, were not detected either at high or at moderate concentrations.

\section{Pesticides with Human-Health Benchmarks}

Pesticides are applied to crops, gardens, lawns, around buildings, and al ong roads

Pesticides to help control unwanted vegetation (weeds), insects, fungi, and other pests. In the San

Diego study unit, all pesticides, which include herbicides, insecticides, and fumigants, were detected only at low concentrations.

\section{BENCHMARKS FOR EVALUATING GROUNDWATER OUALITY}

GA M A's Priority Basin Project uses benchmarks established for drinking water to provide context for evaluating the quality of untreated groundwater. A fter withdrawal, groundwater may be disinfected, filtered, mixed, and exposed to the atmosphere before being delivered to consumers. Federal and $C$ alifornia regulatory benchmarks for protecting human health ( $M$ aximum Contaminant $L$ evel, $M C L$ ) are used for the evaluation when available. Otherwise, non-regulatory benchmarks for protecting aesthetic properties (Secondary M aximum Contaminant L evel, SM CL), such as taste and odor, and non-regulatory benchmarks for protecting human health (Notification L evel, NL, and L ifetime $\mathrm{H}$ ealth Advisory, HAL), are used.

\section{High, moderate, and low concentrations are defined relative to benchmarks}

Concentrations are considered high if they are greater than a benchmark. For inorganic constituents, concentrations are moderate if they are greater than one-half of a benchmark. For organic and special-interest constituents, concentrations are moderate if they are greater than one-tenth of a benchmark; this lower threshold was used because organic constituents generally are less prevalent and have smaller concentrations relative to benchmarks than inorganic constituents. Low includes nondetections and values less than moderate concentrations. M ethods for eval uating water quality are discussed in Wright and B elitz (2011). 


\section{Factors that Affect Groundwater Quality}

The trace elements vanadium (V) and boron (B) were detected at high and moderate concentrations in the San Diego study unit (Wright and B elitz, 2011). High concentrations for these constituents were detected al most exclusively in samples collected in the Temecula Valley study area.

$N$ atural sources of these constituents to groundwater primarily are from the dissolution of rocks. Vanadium is most abundant in mafic rocks, whereas $B$ tends to be most
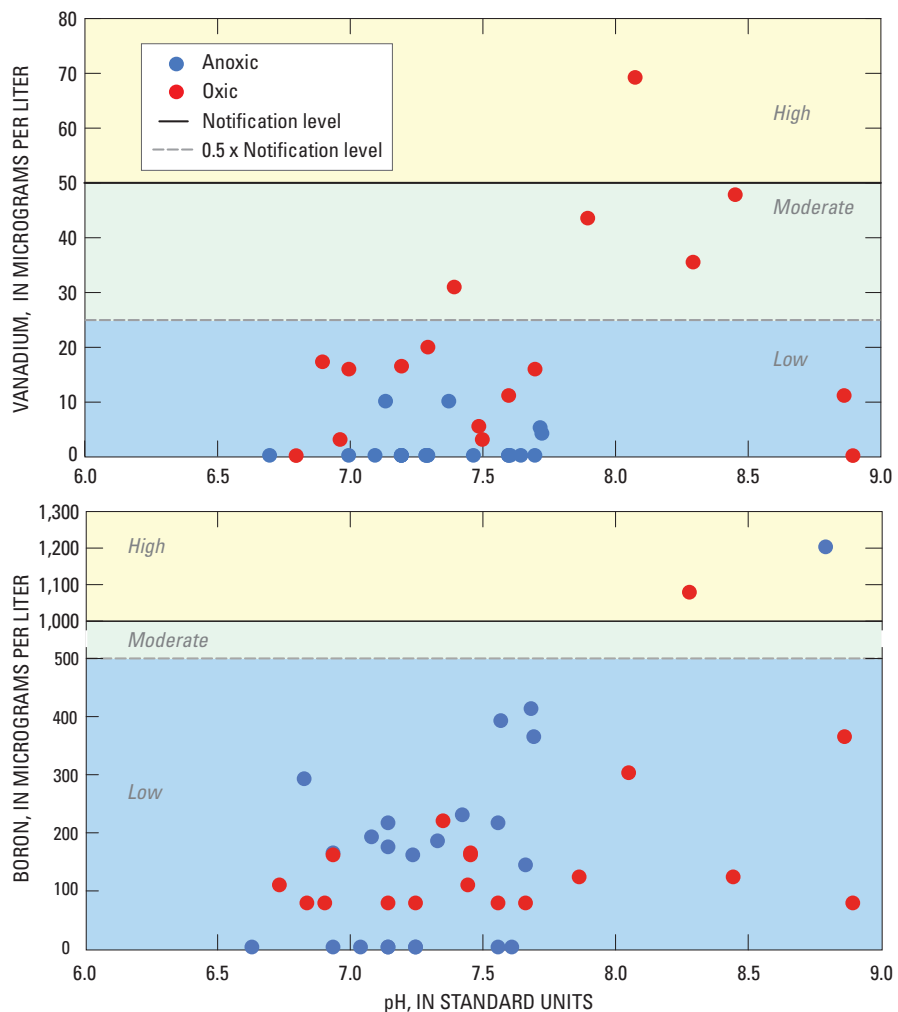
abundant in shale and schist (Reimann and de Caritat, 1998). Potential anthropogenic sources of $\mathrm{V}$ to the environment include the burning of residual crude oil, and the waste streams associated with the ferrous metallurgy industry. Boron is found in cleaning agents and therefore may be present in municipal and industrial wastes. The human-heal th non-regulatory bench marks (notification levels, NL) for $\mathrm{V}$ and $B$ are 50 and 1,000 micrograms per liter, respectively.

The mobility of

$\mathrm{V}$ and $\mathrm{B}$ in groundwater is controlled by the $\mathrm{pH}$ and (or) reduction-oxidation (redox) conditions of the aquifer system. Redox conditions are used to describe whether groundwater has oxidizing (oxic) or reducing (anoxic) conditions.

Vanadium exists in multiple oxidation states in the environment (Hem, 1985); therefore, its molecular structure is affected by both redox and $\mathrm{pH}$. The positive correlation of $\mathrm{V}$ concentrations from samples collected in the San Diego study unit to oxic and alkaline (high $\mathrm{pH}$ ) groundwater conditions was statistically significant (Wright and Belitz, 2011).

B oron does not exist in multiple oxidation states in the environment; therefore, its molecular structure is affected by $\mathrm{pH}$, but not by redox conditions ( $\mathrm{Hem}, 1985)$. The positive correlation of B concentrations from samples collected in the San Diego study unit to alkaline groundwater conditions was statistically significant, but the correlation to redox conditions was not significant (Wright and Belitz, 2011).

\section{By M ichael T. Wright and K enneth B elitz}

\section{SELECTED REFERENCES}

California Department of Water Resources, 2003, California's groundwater: California Department of Water Resources Bulletin 118, 246 p. Available at http://www.water.ca.gov/groundwater/bulletin118/ update2003.cfm.

Hem, J.D., 1985, Study and interpretation of the chemical characteristics of natural water, third edition: U.S. G eological Survey Water-Supply Paper 2254, 213 p.

Reimann, C., and de Caritat, P., 1998, Chemical elements in the environment: B erlin, Springer-Verlag, $399 \mathrm{p.}$

Wright, M .T., B elitz, K enneth, and B urton, C.A., 2005, California GA M A Program-Groundwater quality in the San Diego drainages hydrologic province, California, 2004: U.S. Geological Survey Data Series 129, $91 \mathrm{p}$.

W right, M .T., and B elitz, K enneth, 2011, Status and understanding of groundwater quality in the San Diego Drainages Hydrologic Province, 2004-California GA M A Priority Basin Project: U.S. Geological Survey Scientific Investigations Report 2011-5154, 102 p. Available at http://pubs.usgs.gov/ sir/2011/5154/.
Priority Basin Assessments

GAM A's Priority Basin Project (PBP) assesses water quality in that part of the aquifer system used for drinking water, primarily public supply. Water quality in shallow and deep parts may differ from water quality in the primary aquifers. GAM A's D omestic Well Project assesses water quality in the shallow parts of the aquifer system. Ongoing assessments are being conducted in more than 120 basins throughout California.

The PBP assessments are based on a comparison of constituent concentrations in untreated groundwater with benchmarks established for the protection of human health and for aesthetic concerns. The PB P does not evaluate the quality of drinking water delivered to consumers.

The PBP uses two scientific approaches for assessing groundwater quality. The first approach uses a network of wells to statistically assess the status of groundwater quality. The second approach combines waterquality, hydrologic, geographic, and other data for use in the assessment of the factors that affect water quality. In the San Diego study unit, data were collected by the PBP in 2004 and from the CDPH database for 2001-2004. The PBP includes chemical analyses generally not available as part of regulatory compliance monitoring, including measurements at concentrations much lower than human-health benchmarks, and measurement of constituents that can be used to trace the sources and movement of groundwater.

\section{For more information}

Technical reports and hydrologic data collected for the GA M A Program may be obtained from

\section{GAMA Project Chief}

U.S. Geological Survey

California Water Science Center

4165 Spruance R oad, Suite 200

San Diego, CA 92101

Telephone number: (619) 225-6100

WEB: http://ca.water.usgs.gov/gama

GAMA Program Unit

State Water R esources Control Board

Division of Water Quality

PO B ox 2231, Sacramento, CA 95812

Telephone number: (916) 341-5779

WEB: http://www.waterboards.ca.gov/ water_issues/programs/gama 